\title{
Evaluation of clinicopathological factors in PD-1 response: derivation and validation of a prediction scale for response to PD-1 monotherapy
}

Adi Nosrati ${ }^{1}$, Katy K Tsai ${ }^{1}$, Simone M Goldinger ${ }^{2}$, Paul Tumeh ${ }^{3}$, Barbara Grimes ${ }^{4}$, Kimberly Loo ${ }^{1}$, Alain P Algazi ${ }^{1}$, Thi Dan Linh Nguyen-Kim ${ }^{5}$, Mitchell Levesque ${ }^{2}$, Reinhard Dummer ${ }^{2}$, Omid Hamid ${ }^{6}$ and Adil Daud ${ }^{\star}, 1$

${ }^{1}$ Division of Hematology-Oncology, Department of Medicine, University of California, San Francisco, Mount Zion A-743, 1600 Divisadero Street, San Francisco, CA 94143, USA; ${ }^{2}$ Department of Dermatology, University Hospital of Zurich (USZ), University of Zurich, Gloriastrasse 31, Zürich 8091, Switzerland; ${ }^{3}$ Division of Dermatology, Department of Medicine, University of California Los Angeles (UCLA), 200 Medical Plaza Driveway, Los Angeles, CA 90024, USA; ${ }^{4}$ Department of Epidemiology \& Biostatistics, University of California, San Francisco, 550 16th Street, San Francisco, CA 94158, USA; ${ }^{5}$ Department of Interventional Radiology, University of Zurich, Rämistrasse 100, Zürich, 8091, Switzerland and ${ }^{6}$ The Angeles Clinic and Research Institute (TACRI), 11818 Wilshire Boulevard \#200, Los Angeles, CA 90025, USA

Background: Anti-PD-1 therapy has shown significant clinical activity in advanced melanoma. We developed and validated a clinical prediction scale for response to anti- PD-1 monotherapy.

Methods: A total of 315 patients with advanced melanoma treated with pembrolizumab ( 2 or $10 \mathrm{mg} \mathrm{kg}^{-1} \mathrm{Q} 2 \mathrm{~W}$ or $\mathrm{Q} 3 \mathrm{~W}$ ) or nivolumab ( $3 \mathrm{mg} \mathrm{kg}^{-1} \mathrm{Q} 2 \mathrm{~W}$ ) at four cancer centres between 2011 to 2013 served as the setting for the present cohort study. Variables with significant association to response on a univariate analysis were entered into a forward stepwise logistic regression model and were given a score based on ORs to calculate a clinical prediction scale.

Results: The developed clinical prediction scale included elevated LDH (1 point), age < 65 years (1 point), female sex (1 point), history of ipilimumab treatment ( 2 points) and the presence of liver metastasis $(2$ points). The scale had an area under the receiveroperating curve (AUC) of $0.73(95 \% \mathrm{Cl} 0.67,0.80)$ in predicting response to therapy. The predictive performance of the score was maintained in the validation cohort (AUC $0.70(95 \% \mathrm{Cl} 0.58,0.81)$ ) and the goodness-to-fit model demonstrated good calibration.

Conclusions: Based on a large cohort of patients, we developed and validated a simple five-factor prediction scale for the clinical activity of PD-1 antibodies in advanced melanoma patients. This scale can be used to stratify patients participating in clinical trials.

The treatment of melanoma has been transformed in recent years by novel targeted therapies and immunotherapy. Namely, molecularly targeted combinations for patients with BRAF mutations, such as dabrafenib plus trametinib or vemurafenib plus cobimetinib, and immunotherapies, such as the CTLA-4 blocking antibody ipilimumab (Robert et al, 2015b) and the PD-1

*Correspondence: Professor A Daud; E-mail: adaud@medicine.ucsf.edu Abstract was presented at 2016 ASCO at the poster discussion session.

Received 19 October 2016; revised 22 February 2017; accepted 28 February 2017; published online 21 March 2017

(C) 2017 Cancer Research UK. All rights reserved 0007-0920/17 
blocking antibodies nivolumab and pembrolizumab, have significantly improved survival for patients with advanced melanoma (Robert et al, 2011; Ribas et al, 2015).

The PD-1 receptor is an inhibitory receptor expressed on activated $\mathrm{T}$ and $\mathrm{B}$ cells. Its primary ligand, PD-L1, is frequently expressed within the tumour microenvironment such as cancer cells and tumour-infiltrating macrophages. The second ligand, PD-L2, is preferentially expressed by antigen presenting cells (Blank et al, 2004; Pardoll, 2012; Sullivan et al, 2013).

In the initial phase I clinical trial with nivolumab, Brahmer et al (2010) reported dramatic clinical activity with tumour regressions in several tumour types: colon, renal, lung cancers, and melanoma. Pembrolizumab was initially evaluated in a large phase I trial (KEYNOTE-001). In a pooled analysis of 411 advanced melanoma patients, the response rate was $34 \%$ after a median follow-up of 18 months and was maintained in $81 \%$ of those patients with a median overall survival of 25.9 months (Hamid et al, 2013; Deeks, 2016; Ribas et al, 2016). Results from two other trials, KEYNOTE-002 and KEYNOTE-006, have since been reported (Ribas et al, 2015; Robert et al, 2015b). Two pembrolizumab dosages ( 2 or $10 \mathrm{mg} \mathrm{kg}^{-1}$ every 3 weeks) were compared with investigator's-choice chemotherapy in patients with ipilimumabrefractory advanced melanoma in KEYNOTE-002. Pembrolizumab demonstrated superior progression-free survival compared with chemotherapy (Ribas et al, 2015). Pembrolizumab $\left(10 \mathrm{mg} \mathrm{kg}^{-1}\right.$ every 2 or every 3 weeks) was also compared with ipilimumab ( $3 \mathrm{mg} \mathrm{kg}^{-1}$ every 3 weeks) in 834 advanced melanoma patients in KEYNOTE-006 and found significantly improved overall survival compared with ipilimumab (Robert et al, 2015b). Additionally, nivolumab ( $3 \mathrm{mg} \mathrm{kg}^{-1}$ every 2 weeks) was compared with dacarbazine ( $1000 \mathrm{mg} \mathrm{kg}^{-1}$ every 3 weeks) in a phase 3 , doubleblind, randomised control trial in 418 untreated patients and was associated with significant improvement in overall survival and progression-free survival (Robert et al, 2015a). These trials have established PD-1 antibodies as an important treatment modality for melanoma.

Although PD-1 blockade represents a major step forward, many patients still fail to respond to this drug. The mechanisms underlying this clinical heterogeneity are currently unknown and may be associated with both tumour intrinsic and extrinsic factors (Blank et al, 2016; Pitt et al, 2016). Thus the identification of a clinical predictive model for response is critical due to the following reasons: (1) To allow patients who are unlikely to benefit from anti-PD-1 therapy to be spared from unnecessary risk of toxicity and to rationally select a combination that will better fit them (Hiniker et al, 2015). (2) To spare those who are likely to respond to $\mathrm{PD}-1$ monotherapy from unnecessary toxicities of a combination immunotherapy approach.

Biomarkers associated with both tumour intrinsic and extrinsic factors have been recently investigated, however, none have yet been established to clearly predict response to anti-PD-1 monotherapy (Weide et al, 2016). Previous studies that assayed PD-L1 expression on tumour cells using traditional immunohistochemical approaches reported an association between high expression and clinical response to pembrolizumab (Kefford et al, 2014) or nivolumab (Topalian et al, 2012; Weber et al, 2013; Taube et al, 2014). The tumour immune phenotype has also been investigated, and CD8 ${ }^{+} \mathrm{T}$ cells have been suggested as a potential biomarker in several studies; Tumeh et al (2014) reported that preexisting CD8 ${ }^{+}$ $\mathrm{T}$ cells in the tumour microenvironment were required for tumour regression after treatment with pembrolizumab. Additionally, our group has recently reported relative abundance of 'exhausted' or PD-1/CTLA-4 dual-positive CD8 cells as a biomarker to predict response to anti-PD-1, using a multiparameter flow cytometry on freshly isolated melanoma samples (Daud et al, 2016). Other clinical and pathological factors associated with favourable overall survival were reported recently by Weide et al (2016) and included: low pretreatment values of LDH, limited visceral tumour burden, high relative eosinophil count, and high relative lymphocyte count.

Although some preliminary biomarkers have been suggested, no clinical prediction scale has been created that can be used widely. To fill this gap, we sought to investigate readily available variables and develop and validate a simple clinical prediction scale for response to anti-PD-1 in advanced melanoma patients.

\section{MATERIALS AND METHODS}

Study design. Our study cohort consisted of 337 patients diagnosed with advanced melanoma and treated with either pembrolizumab (2 or $10 \mathrm{mg} \mathrm{kg}^{-1} \mathrm{Q} 2 \mathrm{~W}$ or Q3W) or nivolumab (3 $\left.\mathrm{mg} \mathrm{kg}^{-1} \mathrm{Q} 2 \mathrm{~W}\right)$ at four cancer centres: UCSF, UCLA, The Angeles Clinic and Research Institute (TACRI), and University Hospital of Zürich (USZ) between December 2011 to October 2013. Patients received immunotherapy as part of standard of care treatment or on the following clinical trials: KEYNOTE-001 (NCT01295827), KEYNOTE-002 (NCT01704287), KEYNOTE006 (NCT01866319), or EAP (NCT02083484). All patients enrolled on these trials at any of the four centres were included in our study. Our final cohort consisted of 315 patients with advanced unresectable cutaneous or mucosal melanoma aged $\geqslant 18$ years treated with either pembrolizumab $(N=304)$ or nivolumab $(N=11)$. Patients with uveal melanoma were excluded $(n=22)$. The final data set was divided into derivation and validation cohorts. The derivation cohort consisted of 228 patients from the following institutes: UCSF, UCLA, and USZ. The validation cohort consisted of 87 patients from TACRI (Figure 1). The study was approved by the Institutional Review Board at the University of California, San Francisco, CA, USA.

Data collection. The electronic medical records of the 315 patients were reviewed. Data points collected included, but were not limited to, patient's demographics (sex, age), melanoma primary site, laboratory values (LDH, WBC), AJCC staging, metastatic status, Eastern Cooperative Oncology Group (ECOG) performance status, BRAF mutation status, previous therapies, and best overall response.

Treatment outcomes. The primary outcome measure was tumour response to treatment, which was evaluated using CT imaging at 12 and 16 weeks after the first infusion, and every 12 weeks thereafter. The Response Evaluation Criteria in Solid Tumors (RECIST) version 1.1 was used to define objective clinical responses by a investigatoradjudicated review. Sites of metastases were determined using CT imaging and were not limited to RECIST-defined target lesions. The primary site of melanoma was based on clinical documentation prior to enrollment. Two treatment outcome groups, responders and non-responders, were defined using CT imaging following the treatment. Responders included patients with tumour target lesion that met RECIST v1.1 criteria for complete response (>99\% reduction in the tumour size) or partial response $(\geqslant 30 \%$ radiographic reduction in tumour size). Non-responders included patients with tumour target lesions that met RECIST 1.1 criteria for progression ( $\geqslant 20 \%$ increase in the target lesion) or stable disease ( $<30 \%$ reduction or $<20 \%$ increase in tumour target lesions).

Statistical analysis. Patient characteristics are summarised using means and s.d. for continuous variables and percentages for categorical variables. The final data set was divided into two parts: the derivation and the validation cohorts. The derivation cohort was used to develop the clinical prediction scale for tumour response, and the validation cohort was used to assess how well the scale predicted tumour response. $\mathrm{LDH}$ was analysed by the means of $\mathrm{LDH}$-ratio (LDH value divided by the institutional upper limit of normal). Abnormal LDH was set at a cutoff of ' 1 ' (LDH ratio $>1$ ). 


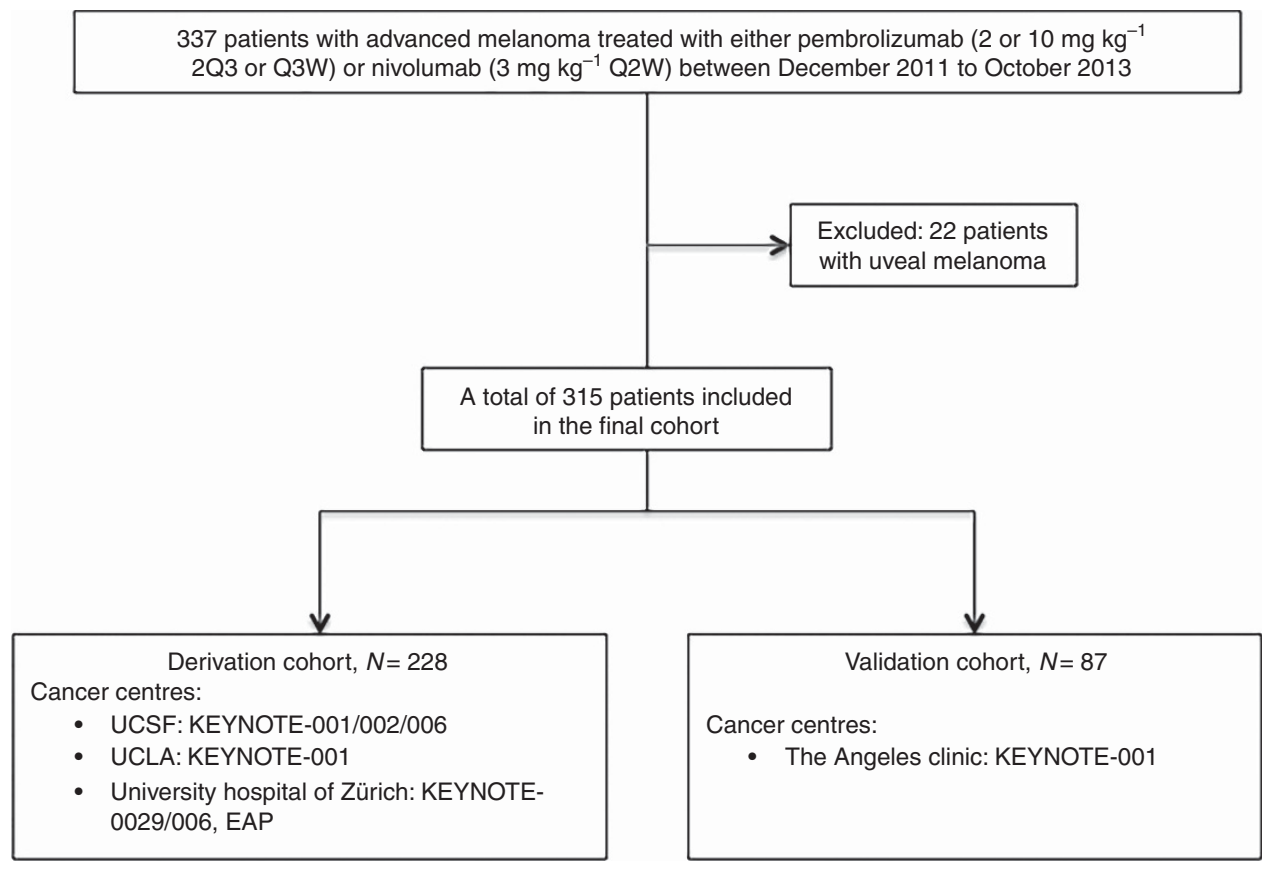

Figure 1. Study participant selection criteria.

Logistic regression was used to assess the possible association between response to anti-PD-1 and the following set of prespecified variables: age, sex, primary site, abnormal LDH, WBC, ECOG performance status, liver metastasis, lung metastasis, brain metastasis, history of ipilimumab treatment, BRAF mutation status, metastatic stage, and history of treatment with targeted therapy.

Variables with significant association on univariate analysis were entered into a stepwise logistic regression model; the $P$ value threshold to enter/leave the model was set to 0.05 . A simple and easy clinical tumour response prediction formula, which produces a score for each subject ranging from 0 to 7 , was developed using the estimated coefficients of the variables in the final model.

To assess the performance of the score, the formula was used to calculate scores for the validation cohort, and the resulting scores were used to predict tumour response. Discrimination of performance of risk index was assessed using area under the receiver-operating curve (AUC). The Hosmer-Lemeshow goodness-of-fit statistic was used to test the calibration.

\section{RESULTS}

Derivation of clinical scale. Demographic and clinical characteristics are summarised in Table 1 . The majority of the derivation cohort patients $(n=228)$ were aged $<65$ years (126 patients, $55.3 \%)$ and male (148 patients, $64.9 \%)$, with M1c metastatic stage $(n=133$, $58.3 \%$ ) and ECOG performance status 0 (157 patients, 68.9\%).

Sixty-eight patients had liver metastasis (29.8\%), 132 patients had lung metastasis (57.9\%) and only 50 patients had brain metastasis (21.9\%). Less than $50 \%$ of patients were treated previously with targeted therapy (54 patients, 23.7\%). However, the majority of patients were treated previously with ipilimumab (147 patients, $64.5 \%$ ). Of the 228 derivation cohort patients, $44.3 \%$ responded to anti-PD-1 therapy (101 of 228) while $55.7 \%$ did not respond (127 of 228).

Table 2 presents all variables associated with response to anti-PD-1 monotherapy on univariate analysis. Age $<65$ years $(\mathrm{OR}=0.42(0.24,0.72), P<0.001)$, elevated $\mathrm{LDH}(\mathrm{OR}=0.38(0.21$, $0.69), P<0.001)$, female sex $(\mathrm{OR}=0.50(0.29,0.89), P=0.01)$, previous ipilimumab treatment $(\mathrm{OR}=0.35(0.20,0.62), P<0.001)$ and liver metastasis $(\mathrm{OR}=0.34(0.17,0.62), P<0.001)$ were significantly associated with lower response to anti-PD-1 therapy. The following variables were tested and found not to be associated with response to anti-PD-1 on univariate analysis: BRAF status $(\mathrm{OR}=0.76 \quad(0.42-1.37, \quad P=0.37)$, brain metastasis $\quad(\mathrm{OR}=0.88$ (0.47-1.67), $P=0.71)$, lung metastasis $(\mathrm{OR}=1.6 \quad(0.94-2.80)$, $P=0.08)$, WBC count $(\mathrm{OR}=0.99(0.47-2.10), P=0.72)$ and metastatic status $(\mathrm{M} 1 \mathrm{~b} ; \mathrm{OR}=1.93 \quad(0.83-4.5) \quad P=0.12, \quad \mathrm{M} 1 \mathrm{c}$; $\mathrm{OR}=0.85 \quad(0.42-1.73), \quad P=0.66, \quad 3 \mathrm{c} ; \quad \mathrm{OR}=1.33 \quad(0.17-01.4)$, $P=0.78)$.

Table 3 presents the Cox regression analysis and the clinical scoring model for response to anti-PD-1 therapy. In the forward stepwise logistic regression model, female sex $(\mathrm{OR}=0.51(0.27$, $0.94), P=0.03)$, age $<65$ years $(\mathrm{OR}=0.55(0.30,0.98), P=0.04)$, previous ipilimumab treatment $(\mathrm{OR}=0.38(0.20,0.69), P<0.001)$, elevated $\mathrm{LDH} \quad(\mathrm{OR}=0.48(0.25,0.90), P=0.02)$ and liver metastasis $(\mathrm{OR}=0.34(0.17,0.66), P<0.001)$ were found to be significant.

A formula (clinical prediction scale) based on the estimated coefficients from the logistic model was derived so that a score ranging from 0 to 7 was calculated for each subject. An increase in the score on the scale corresponded to a significantly lower response to anti-PD-1 therapy $(P<0.05)$. The final clinical prediction scale included 5 prognostic factors that were significantly correlated with lower response: female sex (1 point), age $<65$ years ( 1 point), previous ipilimumab treatment ( 2 points), elevated LDH (1 point), and the presence of liver metastasis (2 points). The developed scale had a fair performance in predicting response to anti-PD-1: AUC 0.73 (95\% CI 0.67, 0.80) (Figure 2A).

Validation of clinical prediction scale. Our scoring model was validated in a separate cohort of patients. The validation cohort included 87 patients diagnosed with advanced melanoma at TACRI. Of the 87 validation cohort patients, $63.3 \%$ responded to anti-PD-1 therapy (55 of 87 ), whereas $36.7 \%$ did not respond (32 of 87). The scale maintained a discrimination power, AUC 0.70 $(95 \%$ CI $0.58,0.81)$ (Figure $2 B)$. Table 4 presents the validation of the clinical prediction scale by response probability. An increase in the score on the scale corresponded to a lower probability of 
Table 1. Patient characteristics of the derivation and validation cohorts

\begin{tabular}{|c|c|c|}
\hline \multirow{2}{*}{ Variable } & \multicolumn{2}{|c|}{ No. $(\%)^{a}$} \\
\hline & Derivation $(n=228)$ & Validation $(n=87)$ \\
\hline \multicolumn{3}{|l|}{ Age, years } \\
\hline $\begin{array}{l}\text { Mean } \pm \text { s.d. } \\
\text { Age }<65 \text { years }\end{array}$ & $\begin{array}{c}62.5 \pm 13.1 \\
126(55.3)\end{array}$ & $\begin{array}{c}62.1 \pm 14.3 \\
51(58.6)\end{array}$ \\
\hline \multicolumn{3}{|l|}{ Sex } \\
\hline $\begin{array}{l}\text { Male } \\
\text { Female }\end{array}$ & $\begin{array}{r}148(64.9) \\
80(35.1)\end{array}$ & $\begin{array}{l}62(71.3) \\
25(28.7)\end{array}$ \\
\hline \multicolumn{3}{|l|}{ Primary site } \\
\hline $\begin{array}{l}\text { Cutaneous } \\
\text { Mucosal } \\
\text { Unknown }\end{array}$ & $\begin{array}{c}200(87.7) \\
13(5.7) \\
15(6.6)\end{array}$ & $\begin{array}{c}68(78.2) \\
11(12.6) \\
8(9.2)\end{array}$ \\
\hline \multicolumn{3}{|c|}{ M category (AJCC 2009) } \\
\hline $\begin{array}{l}\text { Unresectable stage } 3 \\
\text { M1a } \\
\text { M1b } \\
\text { M1c }\end{array}$ & $\begin{array}{r}4(1.8) \\
42(18.4) \\
49(21.5) \\
133(58.3)\end{array}$ & $\begin{aligned} & 3(3.4) \\
8 & (9.2) \\
11 & (12.6) \\
65 & (74.7)\end{aligned}$ \\
\hline \multicolumn{3}{|c|}{ ECOG performance status } \\
\hline $\begin{array}{l}0 \\
1 \\
2 \\
3\end{array}$ & $\begin{aligned} 157 & (68.9) \\
65 & (28.5) \\
5 & (2.2) \\
1 & (0.4)\end{aligned}$ & $\begin{array}{l}75(86.2) \\
12(13.8) \\
0(0.0) \\
0(0.0)\end{array}$ \\
\hline \multicolumn{3}{|l|}{ LDH } \\
\hline $\begin{array}{l}\text { Normal }^{\mathbf{b}} \\
\text { Elevated }^{\mathbf{c}}\end{array}$ & $\begin{array}{r}150(65.8) \\
78(34.2)\end{array}$ & $\begin{array}{l}49(56.3) \\
38(43.7)\end{array}$ \\
\hline \multicolumn{3}{|l|}{ WBC } \\
\hline Mean \pm s.d. & $7.1 \pm 3.5$ & $6.6 \pm 1.9$ \\
\hline \multicolumn{3}{|c|}{ BRAF mutation status } \\
\hline $\begin{array}{l}\text { Negative } \\
\text { Positive } \\
\text { Unknown }\end{array}$ & $\begin{array}{c}162(72.0) \\
63(28.0) \\
3(1.3)\end{array}$ & $\begin{array}{c}56(65.1) \\
30(34.9) \\
1(1.1)\end{array}$ \\
\hline \multicolumn{3}{|l|}{ Liver metastasis } \\
\hline $\begin{array}{l}\text { No } \\
\text { Yes }\end{array}$ & $\begin{array}{r}160(70.2) \\
68(29.8)\end{array}$ & $\begin{array}{l}66(75.9) \\
21(24.1)\end{array}$ \\
\hline \multicolumn{3}{|l|}{ Lung metastasis } \\
\hline $\begin{array}{l}\text { No } \\
\text { Yes }\end{array}$ & $\begin{array}{r}96(42.1) \\
132(57.9)\end{array}$ & $\begin{array}{l}46(52.9) \\
41(47.1)\end{array}$ \\
\hline \multicolumn{3}{|l|}{ Brain metastasis } \\
\hline $\begin{array}{l}\text { No } \\
\text { Yes }\end{array}$ & $\begin{array}{r}178(78.1) \\
50(21.9)\end{array}$ & $\begin{array}{l}71(81.6) \\
16(18.4)\end{array}$ \\
\hline \multicolumn{3}{|c|}{ Previous ipilimumab treatment } \\
\hline $\begin{array}{l}\text { No } \\
\text { Yes }\end{array}$ & $\begin{array}{r}81(35.5) \\
147(64.5)\end{array}$ & $\begin{array}{l}46(52.9) \\
41(47.1)\end{array}$ \\
\hline \multicolumn{3}{|c|}{ Previous targeted therapy } \\
\hline $\begin{array}{l}\text { No } \\
\text { Yes }\end{array}$ & $\begin{array}{r}174(76.3) \\
54(23.7)\end{array}$ & $\begin{array}{l}68(78.2) \\
19(21.8)\end{array}$ \\
\hline \multicolumn{3}{|c|}{$\begin{array}{l}\text { Abbreviations: } A J C C=A m e r i c a n \text { Joint Committee on Cancer; } E C O G=\text { Eastern Coopera- } \\
\text { tive Oncology Group; } L D H=\text { lactate dehydrogenase; } W B C=\text { white blood cell. } \\
\text { a Values are reported as no. (\%) unless otherwise indicated. } \\
b_{\text {Defined as }} \mathrm{LDH} \text { ratio } \leqslant 1 . \\
{ }^{c} \text { Defined as } L D H \text { ratio }>1 .\end{array}$} \\
\hline
\end{tabular}

response; the estimate probability of response for patients who scored ' 6 ' was $29 \%(95 \%$ CI 13, 52) and the estimate probability of response for patients who scored ' 0 ' was $87 \%$ (95\% CI 71, 95). None of the patients in the validation cohort scored ' 7 '.

\section{DISCUSSION}

We developed and validated a clinical prediction scale for response to anti-PD-1 monotherapy. The response index had good
Table 2. Variables significantly associated with response to anti-PD-1 on univariate analysis

\begin{tabular}{|c|c|c|c|}
\hline Source & $\begin{array}{l}\text { Objective } \\
\text { response } \\
\text { rate } \\
\text { (ORR), }{ }^{\text {a } \%}\end{array}$ & $\begin{array}{l}\text { Odds ratio } \\
\text { (OR) }(95 \% \mathrm{Cl})\end{array}$ & $P$ value \\
\hline Total cohort & 44.3 & NA & NA \\
\hline Age $<65$ years & 34.9 & $0.42(0.24,0.72)$ & $<0.001$ \\
\hline Elevated $\mathrm{LDH}^{\mathbf{b}}$ & 29.5 & $0.38(0.21,0.69)$ & $<0.001$ \\
\hline Female sex & 33.8 & $0.50(0.29,0.89)$ & 0.01 \\
\hline Previous ipilimumab treatment & 35.4 & $0.35(0.20,0.62)$ & $<0.001$ \\
\hline Liver metastasis & 26.5 & $0.34(0.17,0.62)$ & $<0.001$ \\
\hline \multicolumn{4}{|c|}{$\begin{array}{l}\text { Abbreviations: } \mathrm{Cl}=\text { confidence interval; } \mathrm{LDH}=\text { lactate dehydrogenase; } \mathrm{NA}=\text { not applic- } \\
\text { able. } \\
\text { a } \mathrm{ORR} \text { was defined as the percentage of patients with a complete or partial response. } \\
{ }^{b} \text { Defined as } L D H \text { ratio }>1 \text {. }\end{array}$} \\
\hline
\end{tabular}

Table 3. Cox regression analysis and clinical scoring model for response to anti-PD-1 therapy

\begin{tabular}{|l|c|c|c|}
\hline Variable & $\begin{array}{c}\text { Odds ratio (OR) } \\
(95 \% \mathrm{Cl})\end{array}$ & $\boldsymbol{P}$ value & Scoring \\
\hline Female & $0.51(0.27,0.94)$ & 0.03 & 1 \\
\hline Age $<65$ years & $0.55(0.30,0.98)$ & 0.04 & 1 \\
\hline Previous ipilimumab treatment & $0.38(0.20,0.69)$ & $<0.001$ & 2 \\
\hline Elevated $\mathrm{LDH}^{\mathrm{a}}$ & $0.48(0.25,0.90)$ & 0.02 & 1 \\
\hline Liver metastasis & $0.34(0.17,0.66)$ & $<0.001$ & 2 \\
\hline $\begin{array}{l}\text { Abbreviations: } \mathrm{Cl}=\text { confidence interval; } \mathrm{LDH}=\text { lactate dehydrogenase. } \\
\text { a Defined as } \mathrm{LDH} \text { ratio }>1 .\end{array}$
\end{tabular}

predictive performance that was maintained in the validation cohort with good calibration. The prediction scale to response to anti-PD-1 was developed using stepwise logistic regression and included five variables that were significantly associated with lower response to anti-PD-1: female sex, age $<65$ years, history of ipilimumab treatment, elevated $\mathrm{LDH}$, and the presence of liver metastasis.

Although anti-PD-1 therapy has transformed the systemic treatment of advanced melanoma, the majority of patients still fail to respond to anti-PD-1 monotherapy; the clinical data indicates that the response rates for patients treated with anti-PD-1 immunotherapy rarely exceed 45\% (Brahmer et al, 2010; Hamid et al, 2013; Ribas et al, 2016). In this study, the response rate of the derivation cohort was about $44.3 \%$, which is consistent with the literature.

As understanding and exploiting this clinical heterogeneity could result in better outcomes, biomarker research remains a very active area of clinical investigation, and characteristics of the tumour microenvironment have been shown to predict response to immunotherapy (Tumeh et al, 2014; Blank et al, 2016; Daud et al, 2016; Pitt et al, 2016). Assays for PD-L1 upregulation and characterisation of a partially exhausted T-cell phenotype, for example, have been strongly associated with effective response to anti-PD-1 (Herbst et al, 2014; Taube et al, 2014; Tumeh et al, 2014; Daud et al, 2016).

To date, however, there is less understanding of the impact of host factors on response to $\mathrm{PD}-1$ blockade. A recent study investigating baseline biomarkers predicting outcomes of pembrolizumab-treated melanoma patients reported a better prognosis for patients with high relative eosinophil count, high relative lymphocyte count, low LDH and the absence of metastasis other than soft tissue/lung (Weide et al, 2016). Additional characteristics, such as age, diet, germline polymorphisms, pre-existing 

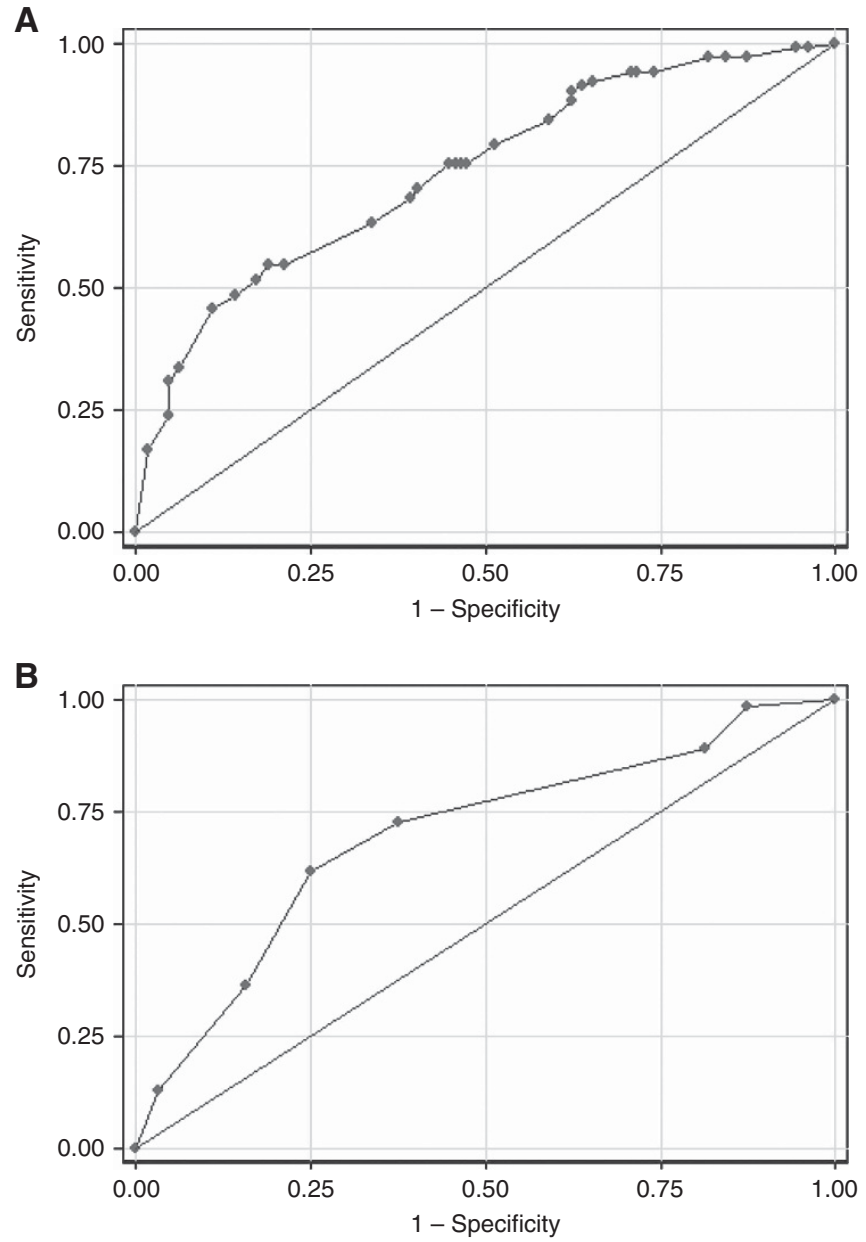

Figure 2. Receiver operation characteristic curve to predict response to immunotherapy. (A) Derivation cohort, area under the curve (AUC) 0.73 (95\% Cl 0.67-0.80). (B) Validation cohort, AUC 0.70 (95\% Cl 0.58-0.81).

immunosuppression and chronic infections, and the gut microbiome have been also proposed to influence response to immune checkpoint inhibition (Pitt et al, 2016; Spranger et al, 2016).

The effect of age, in particular, has been an area of debate. An aging, senescent immune system has been long thought to experience many alterations, including an increase in suppressive immune cell populations, such as MDSCs and Treg cells (Pawelec et al, 2010; Goronzy and Weyand, 2013), and MDSCs have been reported as potential predictors of resistance to ipilimumab therapy (Meyer et al, 2014; Martens et al, 2016), which would suggest a similar effect in anti-PD-1-treated patients.

Interestingly, a recent meta-analysis (Nishijima et al, 2016) comparing efficacy of immune checkpoint inhibition in younger and older patients showed overall survival benefit in both groups, although an exception was seen in a subgroup of older patients in four anti-PD-1 trials who did not demonstrate OS improvement. Although this is different than our findings that younger age is correlated with decreased anti-PD-1 efficacy, it is interesting to note that the age cutoff used for this analysis was $\geqslant 75$ years. Although there was no OS benefit observed in patients aged $\geqslant 75$ years, a consistent survival benefit was still observed in patients aged 65-75 years. Although this observation was made at the metaanalysis level and across a heterogeneous group of clinical trials and needs to be confirmed with adequate power, this preliminary data seems to suggest that patients over a certain age do just as well as their younger counterparts and, in light of our scoring model correlating greater anti-PD- 1 efficacy in patients aged $\geqslant 65$ years,
Table 4. Validation of clinical prediction scale, response

probability $(n=87)$

\begin{tabular}{|c|c|c|c|c|}
\hline \multicolumn{5}{|c|}{ Response, $n(\%)$} \\
\hline $\begin{array}{l}\text { Response } \\
\text { score }\end{array}$ & No & Yes & Total & $\begin{array}{c}\text { Estimated response } \\
\text { probability (\%) } \\
(95 \% \mathrm{Cl})\end{array}$ \\
\hline 0 & $1(12.5)$ & $7(87.5)$ & $8(100)$ & $87(71,95)$ \\
\hline 1 & $4(23.5)$ & $13(76.4)$ & $17(100)$ & $81(66,90)$ \\
\hline 2 & $3(17.6)$ & $14(82.3)$ & $17(100)$ & $72(60,82)$ \\
\hline 3 & $4(40.0)$ & $6(60.0)$ & $10(100)$ & $62(51,72)$ \\
\hline 4 & $14(60.8)$ & $9(39.1)$ & $23(100)$ & $51(37,64)$ \\
\hline 5 & $2(28.5)$ & $5(71.4)$ & $7(100)$ & $39(24,58)$ \\
\hline 6 & $4(80.0)$ & $1(20.0)$ & $5(100)$ & $29(13,52)$ \\
\hline $7^{a}$ & NA & NA & NA & NA \\
\hline Total & $32(36.7)$ & 55 (63.2) & $87(100)$ & NA \\
\hline
\end{tabular}

potentially may have even better response. This observation is certainly hypothesis generating and needs further prospective validation.

The role of sex in response to immunotherapy is also much debated. Although female sex was found to be a negative prognostic indicator in our model, the mechanisms of this remain poorly defined. Indeed, much of the current literature actually supports a survival benefit for females with advanced melanoma, although of note, much of this data preceded the advent of immune checkpoint inhibition (Manola et al, 2000; Dronca et al, 2013; Nosrati and Wei, 2014). Though it is speculated that the increased number and/or improved function of tumour-specific T-helper cells in women could underlie this clinical observation, data regarding the role of sex-hormone modulation of PD-1 are currently limited to preclinical models (Polanczyk et al, 2006, 2007). Further work of this nature needs to be carried out to identify and elucidate the nature of sex-dependent differences in immunoregulatory pathways in patients with advanced cancer (Dronca and Dong, 2015).

Given the relative novelty of this field, the influence of host factors on immunotherapy response requires further research. The factors elucidated in this clinical scale represent one further step in that direction, while also addressing the pressing clinical need for a clinical prediction-scoring model to help guide treatment choice. A model to identify those patients who are likely to respond to antiPD-1 monotherapy would spare them the additional toxicity of combination CTLA-4/PD-1 blockade; conversely, the ability to identify patients who are unlikely to respond to PD-1 monotherapy would also be helpful in determining the most appropriate treatment option. Those patients, for example, may have improved outcomes with molecularly targeted agents (if their melanomas harbour BRAF V600 mutations) or with a more aggressive immunotherapy regimen (combination ipilimumab/nivolumab) or a clinical trial, rather than with an anti-PD-1 agent alone.

Although our study included a large cohort of patients from four different centres, considering the retrospective nature of this study, a patient selection bias cannot be excluded. Additionally, even though our scoring model had a fair prediction probability for response in the validation cohort, this is based on a relatively small sample of patients, and prospective validation with a larger sample is needed. Additionally, the high response rate in our validation cohort $(63.3 \%)$ could have affected the ROC reported in our study. Furthermore, the effect of active brain metastasis on patients' response was not studied as the trials included in our study excluded patients with active brain metastasis. Finally, we could 
not study the effect of pretreatment with ipilimumab in a separate independent model owing to a low number of ipilimumab-naive patients. However, in the four centres included in our study, treatment with pembrolizumab was initiated in a minimum of 6 weeks following the last ipilimumab treatment.

To our knowledge, this is the first clinical scoring model developed to predict response to anti-PD-1 monotherapy. This scoring model was developed in a large cohort of patients who were treated with anti-PD-1 monotherapy and validated in a unique set of patients from a separate facility in an effort to strengthen its external validity. Although biomarker development in immunotherapeutics remains an active area of research, most biomarkers to date require accession of tumour tissue and complex laboratory diagnostics to predict response. With this scale, we sought to create a clinical tool that would be readily accessible in a wide range of clinical settings, without the need for additional biopsies or complex computing.

We acknowledge that our scale is only the beginning and additional data regarding host factors, and tumour characteristics from ongoing studies will greatly help in refining and modifying the current effort.

\section{CONFLICT OF INTEREST}

SMG: Research funding from the Zurich University Hospital and received travel grant support from Novartis, Roche, MSD and BMS. He has an intermittent advisory board relationship with Novartis, Roche, MSD and BMS. PT: Founder and employee at Acteris. APA: Grants for clinical trial support from Merck, BristolMyers Squibb (BMS), Medimmune, AstraZeneca, Oncosec, Acerta, Novartis, and Glaxco SmithKline. RD: Research funding (Novartis, Merck and Co., Inc., Bristol-Myers Squibb, Roche, GlaxoSmithKline) and consultancy or advisory board (Novartis, Merck and Co., Inc., Bristol-Myers Squibb, Roche, GlaxoSmithKline, Amgen). $\mathrm{OH}$ : Consultancy (Amgen, Novartis, Roche, Bristol-Myers Squibb) and speaker (Bristol-Myers Squibb, Genentech, Novartis). AD: Advisory board: Merck Inc., Pfizer Inc., BMS Inc., Novartis, and Genentech Roche. Stock: OncoSec Inc. The other authors declare no conflict of interest.

\section{REFERENCES}

Blank C, Brown I, Peterson AC, Spiotto M, Iwai Y, Honjo T, Gajewski TF (2004) PD-L1/B7H-1 inhibits the effector phase of tumor rejection by $\mathrm{T}$ cell receptor (TCR) transgenic CD8 $+\mathrm{T}$ cells. Cancer Res 64: $1140-1145$.

Blank CU, Haanen JB, Ribas A, Schumacher TN (2016) Cancer immunology. The 'cancer immunogram'. Science 352: 658-660.

Brahmer JR, Drake CG, Wollner I, Powderly JD, Picus J, Sharfman WH, Stankevich E, Pons A, Salay TM, Mcmiller TL, Gilson MM, Wang C, Selby M, Taube JM, Anders R, Chen L, Korman AJ, Pardoll DM, Lowy I, Topalian SL (2010) Phase I study of single-agent anti-programmed death-1 (MDX-1106) in refractory solid tumors: safety, clinical activity, pharmacodynamics, and immunologic correlates. J Clin Oncol 28: 3167-3175.

Daud AI, Loo K, Pauli ML, Sanchez-Rodriguez R, Sandoval PM, Taravati K, Tsai K, Nosrati A, Nardo L, Alvarado MD, Algazi AP, Pampaloni MH, Lobach IV, Hwang J, Pierce RH, Gratz IK, Krummel MF, Rosenblum MD (2016) Tumor immune profiling predicts response to anti-PD-1 therapy in human melanoma. J Clin Invest 126: 3447-3452.

Deeks ED (2016) Pembrolizumab: a review in advanced melanoma. Drugs 76: 375-386.

Dronca RS, Weaver A, Brewer JD, Shuster LT, Kottschade LA, Morita SY, Markovic S (2013) Gender differences in survival from cutaneous melanoma: analysis of United States SEER data, 1992 to 2009. J Clin Oncol 31(Suppl): abstr 9073.
Dronca RS, Dong H (2015) A gender factor in shaping T-cell immunity to melanoma. Front Oncol 5: 8.

Goronzy JJ, Weyand CM (2013) Understanding immunosenescence to improve responses to vaccines. Nat Immunol 14: 428-436.

Hamid O, Robert C, Daud A, Hodi FS, Hwu WJ, Kefford R, Wolchok JD, Hersey P, Joseph RW, Weber JS, Dronca R, Gangadhar TC, Patnaik A, Zarour H, Joshua AM, Gergich K, Elassaiss-Schaap J, Algazi A, Mateus C, Boasberg P, Tumeh PC, Chmielowski B, Ebbinghaus SW, Li XN, Kang SP, Ribas A (2013) Safety and tumor responses with lambrolizumab (anti-PD-1) in melanoma. $N$ Engl J Med 369: 134-144.

Herbst RS, Soria JC, Kowanetz M, Fine GD, Hamid O, Gordon MS, Sosman JA, Mcdermott DF, Powderly JD, Gettinger SN, Kohrt HE, Horn L, Lawrence DP, Rost S, Leabman M, Xiao Y, Mokatrin A, Koeppen H, Hegde PS, Mellman I, Chen DS, Hodi FS (2014) Predictive correlates of response to the anti-PD-L1 antibody MPDL3280A in cancer patients. Nature 515: 563-567.

Hiniker SM, Maecker HT, Knox SJ (2015) Predictors of clinical response to immunotherapy with or without radiotherapy. J Radiat Oncol 4: 339-345.

Kefford R, RA, Hamid O, Robert C, Daud A, Wolchok JD (2014) Clinical efficacy and correlation with tumor PD-L1 expression in patients (pts) with melanoma (MEL) treated with the anti-PD-1 monoclonal antibody MK-3475. ASCO Meeting Abstr 32(Suppl 5): 3005.

Manola J, Atkins M, Ibrahim J, Kirkwood J (2000) Prognostic factors in metastatic melanoma: a pooled analysis of Eastern Cooperative Oncology Group trials. J Clin Oncol 18: 3782-3793.

Martens A, Wistuba-Hamprecht K, Geukes Foppen M, Yuan J, Postow MA, Wong P, Romano E, Khammari A, Dreno B, Capone M, Ascierto PA, Di Giacomo AM, Maio M, Schilling B, Sucker A, Schadendorf D, Hassel JC, Eigentler TK, Martus P, Wolchok JD, Blank C, Pawelec G, Garbe C, Weide B (2016) Baseline peripheral blood biomarkers associated with clinical outcome of advanced melanoma patients treated with ipilimumab. Clin Cancer Res 22: 2908-2918.

Meyer C, Cagnon L, Costa-Nunes CM, Baumgaertner P, Montandon N, Leyvraz L, Michielin O, Romano E, Speiser DE (2014) Frequencies of circulating MDSC correlate with clinical outcome of melanoma patients treated with ipilimumab. Cancer Immunol Immunother 63: 247-257.

Nishijima TF, Muss HB, Shachar SS, Moschos SJ (2016) Comparison of efficacy of immune checkpoint inhibitors (ICIs) between younger and older patients: a systematic review and meta-analysis. Cancer Treat Rev 45: 30-37.

Nosrati A, Wei ML (2014) Sex disparities in melanoma outcomes: the role of biology. Arch Biochem Biophys 563: 42-50.

Pardoll DM (2012) The blockade of immune checkpoints in cancer immunotherapy. Nat Rev Cancer 12: 252-264.

Pawelec G, Derhovanessian E, Larbi A (2010) Immunosenescence and cancer. Crit Rev Oncol Hematol 75: 165-172.

Pitt JM, Vetizou M, Daillere R, Roberti MP, Yamazaki T, Routy B, Lepage P, Boneca IG, Chamaillard M, Kroemer G, Zitvogel L (2016) Resistance mechanisms to immune-checkpoint blockade in cancer: tumor-intrinsic and -extrinsic factors. Immunity 44: 1255-1269.

Polanczyk MJ, Hopke C, Vandenbark AA, Offner H (2006) Estrogenmediated immunomodulation involves reduced activation of effector $\mathrm{T}$ cells, potentiation of Treg cells, and enhanced expression of the PD-1 costimulatory pathway. J Neurosci Res 84: 370-378.

Polanczyk MJ, Hopke C, Vandenbark AA, Offner H (2007) Treg suppressive activity involves estrogen-dependent expression of programmed death-1 (PD-1). Int Immunol 19: 337-343.

Ribas A, Hamid O, Daud A, Hodi FS, Wolchok JD, Kefford R, Joshua AM, Patnaik A, Hwu WJ, Weber JS, Gangadhar TC, Hersey P, Dronca R, Joseph RW, Zarour H, Chmielowski B, Lawrence DP, Algazi A, Rizvi NA, Hoffner B, Mateus C, Gergich K, Lindia JA, Giannotti M, Li XN, Ebbinghaus S, Kang SP, Robert C (2016) Association of pembrolizumab with tumor response and survival among patients with advanced melanoma. JAMA 315: 1600-1609.

Ribas A, Puzanov I, Dummer R, Schadendorf D, Hamid O, Robert C, Hodi FS, Schachter J, Pavlick AC, Lewis KD, Cranmer LD, Blank CU, O'day SJ, Ascierto PA, Salama AK, Margolin KA, Loquai C, Eigentler TK, Gangadhar TC, Carlino MS, Agarwala SS, Moschos SJ, Sosman JA, Goldinger SM, Shapira-Frommer R, Gonzalez R, Kirkwood JM, Wolchok JD, Eggermont A, Li XN, Zhou W, Zernhelt AM, Lis J, Ebbinghaus S, Kang SP, Daud A (2015) Pembrolizumab versus investigator-choice chemotherapy for ipilimumab-refractory melanoma (KEYNOTE-002): a randomised, controlled, phase 2 trial. Lancet Oncol 16: $908-918$. 
Robert C, Long GV, Brady B, Dutriaux C, Maio M, Mortier L, Hassel JC, Rutkowski P, Mcneil C, Kalinka-Warzocha E, Savage KJ, Hernberg MM, Lebbe C, Charles J, Mihalcioiu C, Chiarion-Sileni V, Mauch C, Cognetti F, Arance A, Schmidt H, Schadendorf D, Gogas H, Lundgren-Eriksson L, Horak C, Sharkey B, Waxman IM, Atkinson V, Ascierto PA (2015a) Nivolumab in previously untreated melanoma without BRAF mutation. $N$ Engl J Med 372: 320-330.

Robert C, Schachter J, Long GV, Arance A, Grob JJ, Mortier L, Daud A, Carlino MS, Mcneil C, Lotem M, Larkin J, Lorigan P, Neyns B, Blank CU, Hamid O, Mateus C, Shapira-Frommer R, Kosh M, Zhou H, Ibrahim N, Ebbinghaus S, Ribas A (2015b) Pembrolizumab versus ipilimumab in advanced melanoma. $N$ Engl J Med 372: 2521-2532.

Robert C, Thomas L, Bondarenko I, O'day S, Weber J, Garbe C, Lebbe C, Baurain JF, Testori A, Grob JJ, Davidson N, Richards J, Maio M, Hauschild A, Miller Jr WH, Gascon P, Lotem M, Harmankaya K, Ibrahim R, Francis S, Chen TT, Humphrey R, Hoos A, Wolchok JD (2011) Ipilimumab plus dacarbazine for previously untreated metastatic melanoma. N Engl J Med 364: 2517-2526.

Spranger S, Sivan A, Corrales L, Gajewski TF (2016) Tumor and host factors controlling antitumor immunity and efficacy of cancer immunotherapy. Adv Immunol 130: 75-93.

Sullivan RJ, Lorusso PM, Flaherty KT (2013) The intersection of immunedirected and molecularly targeted therapy in advanced melanoma: where we have been, are, and will be. Clin Cancer Res 19: 5283-5291.

Taube JM, Klein A, Brahmer JR, Xu H, Pan X, Kim JH, Chen L, Pardoll DM, Topalian SL, Anders RA (2014) Association of PD-1, PD-1 ligands, and other features of the tumor immune microenvironment with response to anti-PD-1 therapy. Clin Cancer Res 20: 5064-5074.

Topalian SL, Hodi FS, Brahmer JR, Gettinger SN, Smith DC, Mcdermott DF, Powderly JD, Carvajal RD, Sosman JA, Atkins MB, Leming PD, Spigel DR,
Antonia SJ, Horn L, Drake CG, Pardoll DM, Chen L, Sharfman WH, Anders RA, Taube JM, Mcmiller TL, Xu H, Korman AJ, Jure-Kunkel M, Agrawal S, Mcdonald D, Kollia GD, Gupta A, Wigginton JM, Sznol M (2012) Safety, activity, and immune correlates of anti-PD-1 antibody in cancer. N Engl J Med 366: 2443-2454.

Tumeh PC, Harview CL, Yearley JH, Shintaku IP, Taylor EJ, Robert L, Chmielowski B, Spasic M, Henry G, Ciobanu V, West AN, Carmona M, Kivork C, Seja E, Cherry G, Gutierrez AJ, Grogan TR, Mateus C, Tomasic G, Glaspy JA, Emerson RO, Robins H, Pierce RH, Elashoff DA, Robert C, Ribas A (2014) PD-1 blockade induces responses by inhibiting adaptive immune resistance. Nature 515: 568-571.

Weber JS, Kudchadkar RR, Yu B, Gallenstein D, Horak CE, Inzunza HD, Zhao X, Martinez AJ, Wang W, Gibney G, Kroeger J, Eysmans C, Sarnaik AA, Chen YA (2013) Safety, efficacy, and biomarkers of nivolumab with vaccine in ipilimumab-refractory or -naive melanoma. J Clin Oncol 31: 4311-4318.

Weide B, Martens A, Hassel JC, Berking C, Postow MA, Bisschop K, Simeone E, Mangana J, Schilling B, Di Giacomo AM, Brenner N, Kahler KC, Heinzerling L, Gutzmer R, Bender A, Gebhardt C, Romano E, Meier F, Martus P, Maio M, Blank CU, Schadendorf D, Dummer R, Ascierto PA, Hospers GA, Garbe C, Wolchok JD (2016) Baseline biomarkers for outcome of melanoma patients treated with pembrolizumab. Clin Cancer Res 22(22): 5487-5496.

This work is published under the standard license to publish agreement. After 12 months the work will become freely available and the license terms will switch to a Creative Commons AttributionNonCommercial-Share Alike 4.0 Unported License. 